\section{Introduction to Hydrogen Technology}

by Roman J. Press, K. S. V. Santhanam, Massoud J. Miri, Alla V. Bailey

and Gerald A. Takacs, John Wiley \&

Sons, Hoboken, NJ, USA, 2009,

pp x + 307, ISBN 978-0-471-77985-8,

Price: EUR 64.99, GBP 52.95

In the research institution where I worked for many years, drafts of internal reports were read by at least three independent people before they were printed. Papers intended for external publication were vetted by more than twice this number. This rigorous procedure quickly induced self-discipline to reduce the criticism of ones peers at an early stage. Regrettably, this book shows little sign of critical editing, by the authors themselves or by the publisher.

The book starts off well enough with an introductory chapter on energy resources, the greenhouse effect, nonrenewable and renewable sources and energy storage that sets the scene quite well for a text on hydrogen technology. However, there are already signs of things to come with figures such as 1.24 showing a picture of a hot spring, 1.26 showing a field of maize and references to Wikipedia (an extremely useful source of information but one that I would not class as a primary source).

It is Chapter 2, consisting of 132 pages or over a third of the book, where things go rapidly downhill with much of its contents derived from standard texts on physical and organic chemistry. Some of the physical chemistry has relevance to reactions in fuel cells but it is difficult to see much relevance to the 25 pages devoted to elementary organic chemistry of a level that a 16 year old would not find taxing. On the other hand there is a section on polymers that would warrant expansion. The middle of this chapter has an insert containing a set of figures in colour that are repeats of many of the black and white figures already included. Some of these figures are useful, others such Figure 4.12 (a hydrogen refuelling station which looks suspiciously like a petrol pump), tell the reader nothing.

Chapter 3 starts on page 173 and at last discusses subjects relevant to the book's title; like the preceding chapter it is a curate's egg mixture of the banal and the useful. The second half of the chapter contains the options for hydrogen storage: high pressure cylinders, liquid hydrogen, metal hydrides and storage on carbon nanotubes. Liquid hydrogen has the major disadvantage that a substantial amount of the energy contained in the gas is lost in liquefaction and storage; the hope for the future lies in storage on solid materials. Again this chapter is spoilt by poor figures such as 3.11 and 3.12 and by the author's inability to decide whether to use metal-hydride or metal-hydrate. This latter point could be regarded as mere nitpicking since it is clear that hydrate is wrong but it is symptomatic of the need for editing of the text as a whole.

Chapter 4, entitled "Hydrogen Technology" is short (a mere 28 pages) and gives a concise account of current methods of producing hydrogen which largely depend on the reforming of hydrocarbons and as such offer nothing in the way of renewable energy and reduction of $\mathrm{CO}_{2}$ emissions. The chapter also returns to the topic in the preceding chapter on the storage and distribution of hydrogen which is a problem with currently no really satisfactory solutions. Apart from the trivial figures such as 4.6 showing a "typical landfill view" and 4.12 referred to earlier, this is an excellent chapter. Chapter 5 on fuel cells is a good, if somewhat prolix account of fuel cells. Work on fuel cells has been active from the 1960s and it is clear that many drawbacks still remain, in particular the dependence on platinum metal catalysts. For road vehicles there is the additional problem of the transport of hydrogen. It was not possible to spot the work of the various authors except in this chapter where the idiosyncratic use of the English language (particularly the paucity of the use of the definite article) leads me to guess that it was written by the author whose native language is Russian. The book ends with a short chapter on the current applications of fuel cells.

It is one of my favourite aphorisms which I have used before in these pages that if it were half as long it would be twice as good and this certainly applies here. More rigorous editing would have reduced the dross and concentrated the gold in this book and I can only hope that the publishers will bring back their copy editors to deal with a second edition.

E. R. Adlard 